Original Research Article

\title{
A study of the neuroprotective role of Punica granatum and rosuvastatin in scopolamine induced cognitive deficit in rats
}

\author{
Fariha Fatima, Dilshad A. Rizvi*, Afroz Abidi, Ali Ahmad, Pooja Shukla, \\ Fardan Qadeer, Karan Srivastava
}

Department of Pharmacology, Era's Lucknow Medical College and Hospital, Lucknow, Uttar Pradesh, India

Received: 08 May 2017 Accepted: 02 June 2017

*Correspondence to: Dr. Dilshad A. Rizvi, Email: dr.dilshadali@ yahoo.com

Copyright: () the author(s), publisher and licensee Medip Academy. This is an openaccess article distributed under the terms of the Creative Commons Attribution NonCommercial License, which permits unrestricted noncommercial use, distribution, and reproduction in any medium, provided the original work is properly cited.

\begin{abstract}
Background: The present work has been planned to find out the effect of Punica granatum and Rosuvastatin on learning and memory in Scopolamine induced cognitive deficits in rats. Scopolamine being an anticholinergic agent is used fervently in experimental models for memory deficits and has been widely implicated for the screening of cognitive dysfunction. Punica granatum (Pomegranate) has shown to suppress tumor neuronal cells, hence it can be a potential agent in providing neuroprotection for preventing the development and progression of $\mathrm{AD}$. There are conflicting reports indicating the role of statins as a neuroprotective agent. This contradiction led us to investigate the effect of the role of Rosuvastatin on memory. The test agents were further compared to the standard treatment group acetylcholinesterase inhibitor i.e. Donepezil.

Methods: Male wistar rats 150-200gms were divided into 4 groups of 6 rats each. Amnesia was induced by scopolamine $3 \mathrm{mg} / \mathrm{kg}$ ip at day 5 in all the groups. Group1 (amnesic control) given distilled water; group 2(standard treatment i.e. Donepezil $0.5 \mathrm{mg} / \mathrm{kg}$ orally); group 3 (Rosuvastatin group $10 \mathrm{mg} / \mathrm{kg}$ orally); group 4 (Punica granatum juice $500 \mathrm{mg} / \mathrm{kg}$ orally) The methods for validating cognition deficits were behavioural tests like Cook's pole response and Passive Avoidance response.

Results: It was evident from our research that the Punica granatum juice and Rosuvastatin effectively antagonized the scopolamine induced cognitive impairment in the paradigms studied. The neuroprotective effect of Punica granatum juice was better as compared to the Rosuvastatin group and the effects of the former were comparable with the standard treatment i.e. Donepezil group.

Conclusions: Punica granatum has a remarkable protective role in memory function, learning, cognition and behavior in Scopolamine induced amnesia model of Alzheimer's disease which was better than Rosuvastatin treatment.
\end{abstract}

Keywords: Amnesia, Cognition, Cook's pole apparatus, Punica granatum, Passive avoidance response apparatus, Scopolamine

\section{INTRODUCTION}

Cognitive dysfunction is the most common neurological disorder encountered in clinical practice affecting memory, learning, perception and problem solving including amnesia, dementia and delirium. It is found to be related to Alzheimer's disease (AD), epilepsy, depression, schizophrenia and stroke. ${ }^{1} \mathrm{AD}$ is the fourth leading cause of death worldwide characterized by a decline in cognitive functions that affects an individual's ability to perform daily activities. This decline occurs because neurons involved in cognitive functions get damaged. ${ }^{2,3}$ The pathophysiology of $\mathrm{AD}$ is directly related to the cholinergic loss of neurons beginning in the hippocampal region which is involved in memory and learning and progressing towards the dilatation of ventricles and shrinkage of cortex. ${ }^{4}$

Current treatment is aimed at alleviating the symptoms only failing to target its cure. Augmenting of cholinergic 
transmission is currently the mainstay of therapy. Drugs used for this purpose are cholinesterase inhibitors like Donepezil, Rivastigmine and Galantamine which are being used fervently in mild to moderate disease. ${ }^{5,6}$ It is proposed that statins play a beneficial role in $\mathrm{AD}$ pathology due to its potent cholesterol lowering mechanisms which alter amyloid precursor protein and beta amyloid plaque levels. ${ }^{7,8}$

Scopolamine being an anticholinergic agent is used fervently in experimental models for memory deficits and has been widely implicated for the screening of antidementia agents. ${ }^{9}$

The use of certain fruits has shown to possess powerful neuroprotective properties. One such being Punica granatum (commonly known as Pomegranate) which apart from helping in conditions like hypertension, hypercholesterolemia, oxidative stress, hyperglycemia and inflammation, it has also shown to suppress SK-NSH neuronal cells and hence it can be a potential agent in preventing the development and progression of $\mathrm{AD} .{ }^{10-12}$

Keeping this view in mind, present study has been carried out to evaluate the effect of Punica granatum juice and Rosuvastatin against scopolamine induced memory deficit through behavioural paradigms like Passive Avoidance Response and Cook's Pole Climbing Response.

\section{METHODS}

Animals used in the study were Male Wistar rats (Rattus norvegicus) of 150-200gm weight.

Animals were obtained from CPCSEA-certified animal house (CDRI, Lucknow).

The animals were maintained in cages, under a temperature of $25 \pm 2{ }^{\circ} \mathrm{C}$ and $45-55 \%$ relative humidity, with a 12 -hour light/dark cycle.

They were fed with standard pellet diet and water ad libitum.

\section{Authentication of plant material and preparation of extract $^{13,14}$}

The fruit was purchased from the market and was authenticated at NBRI, Lucknow. Juice from fresh Punica granatum fruit was extracted by squeezing the pulp and was collected in a separate container. The dose of juice extract was taken to be $500 \mathrm{mg} / \mathrm{kg}$ body and was administered via oral gavage tube.

\section{Rosuvastatin}

It was purchased from local market and was pulverized and dissolved in distilled water and administered to experimental animals via oral gavage tube. Dose of Rosuvastatin was taken to be $10 \mathrm{mg} / \mathrm{kg} .{ }^{15}$

\section{Standard treatment}

\section{Donepezil}

It was purchased from local market and was pulverized and dissolved in distilled water and administered to experimental animals via oral gavage tube. The dose of Donepezil was taken as $0.5 \mathrm{mg} / \mathrm{kg}$ body weight orally till day 5.16

\section{Induction of amnesia}

Scopolamine $(3 \mathrm{mg} / \mathrm{kg}$ ) was purchased from market and was administered intraperitoneally, to study its effect on acquisition in separate groups $(n=6), 30$ minutes prior to the trial. ${ }^{17}$

\section{Experimental protocol}

The rats were trained for 1 week prior to the start of the experiment. They were divided into 4 groups of 6 rats each. Total of 24 rats were taken. Behavioural assessment was done in rats at the start of the experiment i.e. at day 0 .

The rats were pretreated with the test and standard drugs for 5 days, following which injection Scopolamine $3 \mathrm{mg} / \mathrm{kg}$ i.p. was administered in all the groups and behavioural assessment on the Cook's Pole Climbing Response apparatus, Morris Water Maze Response and Passive Avoidance Response Apparatus 30 minutes after the induction of amnesia was carried out.

The groups were divided as follows:

- Group 1: Amnesic control (Scopolamine 3mg/kg, i.p. on day $5+\mathrm{D}$.W orally by oral gavage tube from day 1 till day 5)

- Group 2: Standard Treatment (Scopolamine 3mg/kg, i.p. on day $5+$ Donepezil $(0.5 \mathrm{mg} / \mathrm{kg}$ orally by oral gavage tube from day 1 till day 5)

- Group 3: Rosuvastatin (Scopolamine 3mg/kg, i.p. on day $5+$ Rosuvastatin $10 \mathrm{mg} / \mathrm{kg}$ orally by oral gavage tube from day 1 till day 5)

- Group 4: Punica granatum Juice (Scopolamine $3 \mathrm{mg} / \mathrm{kg}$, i.p. on day 5+ Punica granatum Juice $500 \mathrm{mg} / \mathrm{kg}$ orally by oral gavage tube from day 1 till day 5).

\section{Behavioral analysis}

Behavioral tests were performed to functionally validate cognitive dysfunction amnestic models and to assess treatments. 
Following methods to assess hippocampus-dependent memory functions were used:

\section{Cook's pole climbing apparatus}

The rats were trained for conditioned avoidance response by using Cook's Pole Climbing Apparatus. Each rat was allowed to acclimatize and explore the apparatus for 1 minute. The buzzer was then sounded. 5 seconds after switching on the buzzer, mild electric shocks were administered through the stainless steel grid floor. The time taken by the rat to climb the wooden pole in the center known as "escape latency" is recorded. As soon as the rat climbed the pole, both the buzzer and foot-shock were switched off. ${ }^{18,19}$ Escape latency in seconds was recorded as end point measure.

\section{Passive avoidance response}

The animals were subjected to a single trial as per Sakurai M. et al, 2008. The response was recorded to examine the long-term memory. The apparatus consisted of a box $(27 \mathrm{~cm} \times 27 \mathrm{~cm} \times 27 \mathrm{~cm})$ having three walls of wood and one wall of Plexiglas, featuring a grid floor (made up of $3 \mathrm{~mm}$ stainless-steel rods set $8 \mathrm{~mm}$ apart), with a wooden platform $(10 \mathrm{~cm} \times 7 \mathrm{~cm} \times 1.7 \mathrm{~cm})$ in the center of the grid floor. The box was illuminated with a $15 \mathrm{~W}$ bulb during the experimental period. Electric shock was delivered to the grid floor. A wooden platform was placed on the grid floor carrying foot shock $(50 \mathrm{~Hz}, 1.5$ $\mathrm{mA})$. Each rat is placed on the wooden platform. The time taken by the rat to step down and place all four paws on the grid floor carrying shock known as "step down latency" in seconds is recorded as end point. ${ }^{20}$

\section{Statistical analysis}

The data obtained was tabulated and subjected to descriptive analysis. The different groups were compared using ANOVA (Analysis of variance) followed by Post Hoc Dunnet T3 Test. Values before and after treatment in each group were compared using Paired ' $\mathrm{T}$ ' test. All statistical analysis was done using Graph pad Prism software (version 6.02). $\mathrm{p}$ value $<0.05$ was considered as significant.

\section{RESULTS}

\section{Effect of test drugs on escape latency by Cook's Pole Apparatus}

No significant change was observed on baseline behaviour in terms of escape latency in any of the groups $(\mathrm{p}=0.262)$ at day 0 (Table 1$)$.

A statistically significant increase in the escape latency on the 5th day was observed when its values were compared to the baseline behaviour $(p=0.0017)$ i.e., at day 0 in the control group. Whereas no significant difference was observed in the standard treatment group,
Rosuvastatin group and PJ at Day 5 from the baseline. A significantly higher escape latency was observed in the control group when compared to the standard treatment group $(\mathrm{p}<0.0001)$ at day 5 after administration of inj scopolamine whereas, the rest of the groups (Standard treatment group, Rosuvastatin group and PJ group) showed comparable results with the standard treatment group i.e. Donepezil. On comparison with the control group, a statistically significant improvement in the mean escape latencies in all the groups was observed $(\mathrm{p}<0.0001)$ (Table 1).

Table 1: Effect of test drugs on escape latency by Cook's Pole Apparatus at day 5.

\begin{tabular}{|c|c|c|c|c|c|}
\hline \multirow{2}{*}{ Groups } & Day 0 & & Day 5 & & \multirow{2}{*}{$\begin{array}{l}\text { Paired } \\
\text { T test: } \\
\text { p value }\end{array}$} \\
\hline & \multicolumn{4}{|c|}{ Mean (sec) $95 \%$ CI } & \\
\hline Control & 4.8 & $\begin{array}{l}4.245- \\
5.355\end{array}$ & $11.67 * *+$ & $\begin{array}{l}8.957- \\
14.38\end{array}$ & 0.0017 \\
\hline $\begin{array}{l}\text { STD } \\
\text { treatment }\end{array}$ & 5.6 & $\begin{array}{l}2.741- \\
8.459\end{array}$ & 5.833\# & $\begin{array}{l}4.026- \\
7.641\end{array}$ & $>0.9999$ \\
\hline Rosuvastatin & 6.6 & $\begin{array}{l}3.132- \\
10.07\end{array}$ & 8.333\# & $\begin{array}{l}6.269- \\
10.39\end{array}$ & 0.0972 \\
\hline PG juice & 7.2 & $\begin{array}{l}6.161- \\
8.239\end{array}$ & $4.5 \#$ & $\begin{array}{l}2.908- \\
6.092\end{array}$ & 0.0816 \\
\hline $\begin{array}{l}\text { Anova } \\
\text { F value }\end{array}$ & 1.425 & & 14.33 & & \\
\hline $\mathrm{p}$ value & 0.262 & & $<0.0001$ & & \\
\hline $\begin{array}{l}\text { ** When con } \\
\text { \# When comp } \\
+ \text { When com } \\
\text { Punica grana }\end{array}$ & $\begin{array}{l}\text { pared wi } \\
\text { ared with } \\
\text { ared to } \\
\text { um juice }\end{array}$ & $\begin{array}{l}\text { th standa } \\
\text { a control } \\
\text { day } 0 ; \mathrm{p}\end{array}$ & $\begin{array}{l}d ; p<0.05 \\
p<0.05 \\
<0.05 \text { (STD: }\end{array}$ & . & J Juice: \\
\hline
\end{tabular}

\section{Effect of test drugs on step down latency by Passive Avoidance Response}

There was no significant difference in the baseline behaviour of rats at day 0 in terms of mean step down latency in any of the groups $(\mathrm{p}=0.6704)$ (Table 2).

Table 2: Effect of test drugs on step down latency by Passive Avoidance Response at day 5.

\begin{tabular}{|c|c|c|c|c|c|}
\hline \multirow[b]{2}{*}{ Groups } & Day & & Day 5 & & \multirow{2}{*}{$\begin{array}{l}\text { Paired } \\
\text { T test: } \\
\text { p value }\end{array}$} \\
\hline & \multicolumn{4}{|c|}{ Mean (sec) $95 \%$ CI } & \\
\hline Control & 1.8 & $\begin{array}{c}0.7611 \\
-2.839\end{array}$ & $1.167 * *$ & $\begin{array}{l}-0.2282- \\
2.562\end{array}$ & 0.2980 \\
\hline $\begin{array}{l}\text { STD } \\
\text { treatment }\end{array}$ & 4.2 & $\begin{array}{l}1.236- \\
7.164\end{array}$ & $16 \#+$ & $\begin{array}{l}6.133- \\
25.87\end{array}$ & 0.0167 \\
\hline Rosuvastatin & 5.6 & $\begin{array}{l}3.18- \\
8.02\end{array}$ & $12 \#+$ & $\begin{array}{l}8.365- \\
15.64\end{array}$ & 0.0046 \\
\hline PG juice & 3.6 & $\begin{array}{l}2.184- \\
5.016\end{array}$ & $19.17 \#+$ & $\begin{array}{l}17.02- \\
21.31\end{array}$ & $<0.0001$ \\
\hline $\begin{array}{l}\text { Anova } \\
\text { F value }\end{array}$ & 0.59 & & 15.26 & & \\
\hline $\mathrm{p}$ value & 0.67 & & $<0.0001$ & & \\
\hline
\end{tabular}

** When compared with standard; $\mathrm{p}<0.05$

\# When compared with control; $\mathrm{p}<0.05$

+ When compared to day $0 ; \mathrm{p}<0.05$ (STD: standard, PG Juice:

Punica granatum juice) 
An improvement in memory, cognition and behaviour was seen in pretreated groups (Standard treatment, Rosuvastatin and PJ groups) at day 5 depicted by a significant increase in step down latency time from the baseline at day $0 . \quad(\mathrm{p}=0.0167, \quad 0.0046,<0.0001$, respectively) (Table 2).

All the groups showed a statistically significant increase in the step down latencies as compared to the Control group at day $5(\mathrm{p}<0.0001)$. The Control group showed significant reduction in the mean step down latency in comparison to the standard treatment group $(\mathrm{p}<0.0001)$ while the rest of the groups Rosuvastatin and PJ showed comparable results with the latter. Mean baseline values of step down latencies at day 0 did not vary significantly amongst different groups ( $\mathrm{p}=0.6704)$ (Table 2).

\section{DISCUSSION}

Present study was done to discern the effects of the test substances Punica granatum juice and Rosuvastatin in memory deficits associated with dementia in an experimental model of Alzheimer's disease in comparison to its standard treatment i.e. Donepezil.

Administration of Scopolamine at day 5 in groups pretreated with Standard treatment, Rosuvastatin, PJ and vehicle led to attenuation of memory function, learning skills and behaviour in comparison to the baseline parameters at day 0. Scopolamine is capable of inducing various behavioural changes in several animal species due to its anticholinergic effect leading to the depletion of acetylcholine neurotransmitter. ${ }^{17,19}$

In our study the Rosuvastatin group showed a considerable neuroprotection in response to Cook's Pole Climbing Response apparatus and Passive Avoidance Response apparatus compared to the Control group but the improvement in dementia was not as pronounced as the Standard treatment group. The rats pretreated with Rosuvastatin showed amelioration of memory functions at day 5 when amnesia was induced by Scopolamine. A possible mechanism which is through the inhibition of HMG-CoA reductase, statins ultimately prevent the endogenous production of cholesterol. Several evidences from cell culture and in-vivo animal studies state that cholesterol can inhibit $\beta$ amyloid synthesis. ${ }^{21}$

Treatment with Punica granatum juice showed a neuroprotective effect in Scopolamine induced amnesia as well as in High Fat Diet induced model of Alzheimer's disease. It led to the amelioration of memory function and behaviour in the Punica granatum pretreated groups in Scopolamine induced amnesia at day 5. It has been reported that the neuroprotective effects of many polyphenols present in Punica granatum fruit has ability to permeate brain barrier and directly scavenge pathological concentration of reactive oxygen and nitrogen species and chelate transition metal ions, hence, aiding in neuroprotection. ${ }^{22}$
In our study Donepezil showed statistically significant improvement in cognition and memory in experimental models. Neurotransmitter enhancement therapy with ChEIs (cholinesterase inhibitors) is a treatment approach for patients with mild to moderate AD. The treatment is aimed to improve the cognitive outcome of the disease such as memory loss, clinical global impression, activities of daily living and behaviour. ${ }^{23,24}$

A substantial neuroprotection offered by Punica granatum juice and Rosuvastatin in combatting memory loss and cognitive dysfunction induced by scopolamine has been recorded in our research. To the best of our knowledge this effect has not been reported earlier and this is the first report of amelioration by Punica granatum and Rosuvastatin in Scopolamine induced amnesia model of Alzheimer's disease as compared to the standard treatment i.e. Donepezil.

\section{CONCLUSION}

Hence, we conclude that Punica granatum has a remarkable protective role in memory function, learning, cognition and behaviour in Scopolamine induced amnesia model of Alzheimer's disease which was better than the Rosuvastatin treatment.

Longer, more specific and dose responsive animal and human studies are required to further strengthen our present conclusion and to unveil the concerned mechanisms of actions of Punica granatum and Rosuvastatin in either halting the disease progress or preventing it.

\section{ACKNOWLEDGMENTS}

Authors are highly obliged to Dr. MT Salman (Associate Professor, University of Medical Sciences Dammam) and Dr. Afroz Abidi (Associate Professor, Department of Pharmacology, Era's Lucknow Medical College and Hospital) for their unconditional help and support.

Funding: No funding sources Conflict of interest: None declared

Ethical approval: The study was approved by the Institutional Animal Ethics Committee of Era's Lucknow Medical College as per the guidelines of Animal Care by CPCSEA. Approval No: ELMC/PHAR/IAEC-11

\section{REFERENCES}

1. Demetrius LA, Magistretti PJ, Pellerin. Alzheimer's disease. The amyloid hypothesis and the Inverse Warburg effect. Front Physiol. Jan 2014;5:522.

2. Campos C. Treatment of Cognitive Deficits in Alzheimer's disease: A psychopharmacological review. Psychiatr Danub. 2016 Mar;28(1):2-12.

3. Danysz W, Parsons CG. Alzheimer's disease, $\beta$ amyloid, glutamate, NMDA receptors and 
memantine--searching for the connections. $\mathrm{Br} \mathrm{J}$ Pharmacol. 2012 Sep;167(2):324-52.

4. Can Z. Natural Compounds That Modulate BACE1processing of Amyloid-beta Precursor Protein in Alzheimer's disease. Discov Med. 2012 Sep;14(76):189-97.

5. Johannsen P. Long-term cholinesterase inhibitor treatment of Alzheimer's disease. CNS Drugs. 2004;18(12):757-68

6. McGleenon BM, Dynan KB, Passmore AP. Acetylcholinesterase inhibitors in Alzheimer's disease. British journal of clinical pharmacology. 1999 Oct 1;48:471-80.

7. Bierer LM, Haroutunian V, Gabriel S. Neurochemical correlates of dementia severity in Alzheimer's disease: relative importance of the cholinergic deficits. Journal of Neurochemistry. 1995;64(2):749-60.

8. Ginsberg J, Ramakrishnan R, Desnick RJ. Suppression of apolipoprotein B production during treatment of cholesteryl ester storage disease with lovastatin. Implications for regulation of apolipoprotein B synthesis. J. Clin. Investig. 1987;80:1692-7.

9. Grundy SM. Consensus statement: role of therapy with "statins" in patients with hypertriglyceridemia. The American J of Car. 1998 Feb 26;81(4):1B-6B

10. Lad V, Frawley D, Santa Fe NM. The Yoga of Herbs. Lotus Press; 1986:135-136.

11. Lansky EP, Newman RA. Punica granatum (pomegranate) and its potential for prevention and treatment of inflammation and cancer. J Ethnopharmacol. 2007;109:177-206.

12. Jurenka JS. Therapeutic applications of pomegranate (Punica granatum L.): a review. Altern Med Rev. 2008 Jun;13(2):128-44.

13. Jimenez DR, Ramazanov A, Sikorski S, Ramazanov Z, Chkhikvishvili I. A new method of standartization of health-promoting pomegranate fruit (Punica granatum) extract. Georgian medical news. 2006 Nov(140):70-7.

14. Forouzanfar F, Goli A, Asadpour E, Ghorbani A, Sadeghnia HR. Protective effect of Punica granatum L. against serum/glucose deprivation-induced PC12 cells injury. Evidence-Based Complementary and Alternative Medicine. 2013 Jul 7; 2013.

15. Maria T, Kotetarova G, Kostadinova II. Effect of Atorvastatin and Rosuvastatin on Learning and
Memory in Rats with Diazepam-Induced Amnesia. Folia Med. 2013;55(2):58-65.

16. Ogura H, Kosasa T, Araki S, Yamanishi Y. Pharmacological properties of donepezil hydrochloride (Aricept), a drug for Alzheimer's disease. Nihon Yakurigaku Zasshi. 2000 Jan;115(1):45-51.

17. Agrawal R, Tyagi E, Saxena G, Nath C. Cholinergic influence on memory stages: A study on scopolamine amnesic mice. IJP. 2009;41(4):192-6.

18. Webster S, Bachstetter A, Nelson P, Schmitt F, Van Eldik L. Using mice to model Alzheimer's dementia: an overview of the clinical disease and the preclinical behavioral changes in 10 mouse models. Front Genet. 2014:5.

19. Malabade R, Taranalli A. Procera C. A potential cognition enhancer in scopolamine and electroconvulsive shock-induced amnesia in rats. Indian J of Phar. 2015;47(4):419.

20. Desai KM, Bhavsar VH, Dhumal VR, Kelkar VV. Disruptive effects of repeated electroconvulsive shock on retention of learned active avoidance is attenuated by carbamazepine. IRCS Med Sci. 1983;11:516-7.

21. Jick H, Zornberg GL, Jick SS, Seshadri S, Drachman DA. Statins and the risk of dementia. Lancet. 2000;356:1627-31.

22. Tran HN. Pomegranate (Punica granatum) seed linolenic acid isomers: concentration-dependent modulation of estrogen receptor activity. Endocr Res. 2010 Jan;35(1):1-16.

23. Courtney C, Farrell D, Gray R. Long-term donepezil treatment in 565 patients with Alzheimer's disease (AD2000): randomised double-blind trial. The Lancet. 2004;363(9427):2105-15.

24. Albert M, DeKosky ST, Dickson D, Dubois B, Feldman H, Fox NC, et al. The diagnosis of mild cognitive impairment due to Alzheimer's disease: report of the National Institute on Aging and the Alzheimer's Association workgroup. Alzheimers Dement. 2011;7(3):270-9.

Cite this article as: Fariha F, Rizvi DA, Abidi A, Ahmad A, Shukla P, Qadeer F, et al. A study of the neuroprotective role of Punica granatum and rosuvastatin in scopolamine induced cognitive deficit in rats. Int J Basic Clin Pharmacol 2017;6:1773-7. 